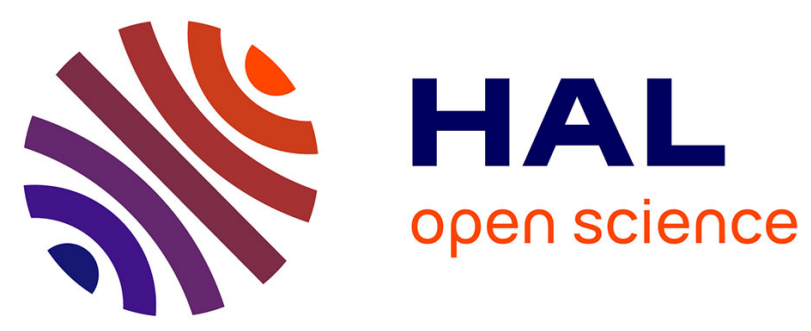

\title{
Dynamic exergoeconomic analysis of a solar district heating system located in the North West of France
}

Mathilde Veyron, Daniel Mugnier, Fabrice Renaude, Marc Clausse

\section{To cite this version:}

Mathilde Veyron, Daniel Mugnier, Fabrice Renaude, Marc Clausse. Dynamic exergoeconomic analysis of a solar district heating system located in the North West of France. ECOS 2021, 34th International Conference on Efficiency, Cost, Optimisation, Simulation and Environmental Impact of Energy Systems, Jun 2021, Giardini Naxos, Italy. hal-03473100

\section{HAL Id: hal-03473100 \\ https: / hal-insa-lyon.archives-ouvertes.fr/hal-03473100}

Submitted on 9 Dec 2021

HAL is a multi-disciplinary open access archive for the deposit and dissemination of scientific research documents, whether they are published or not. The documents may come from teaching and research institutions in France or abroad, or from public or private research centers.
L'archive ouverte pluridisciplinaire HAL, est destinée au dépôt et à la diffusion de documents scientifiques de niveau recherche, publiés ou non, émanant des établissements d'enseignement et de recherche français ou étrangers, des laboratoires publics ou privés. 


\title{
Dynamic exergoeconomic analysis of a solar district heating system located in the North West of France
}

\author{
Mathilde Veyron ${ }^{a}$, Daniel Mugnier ${ }^{b}$, Fabrice Renaude ${ }^{c}$ and Marc \\ Clausse $^{a}$ \\ a Univ. Lyon, CNRS, INSA Lyon, CETHIL, UMR5008, 69621 Villeurbanne, France, \\ mathilde.veyron@insa-lyon.fr, CA \\ b TECSOL, 105 av Alfred Kastler, 66100 Perpignan, France, daniel.mugnier@tecsol.fr \\ c CYLERGIE, 18 avenue Tony Garnier, 69007 Lyon, France, fabrice.renaude@engie.com
}

\begin{abstract}
Solar thermal energy is a possible technology in order to increase the renewable share inside district heating as required by European Directive 2012/27. However, these systems represent an important investment and need to be appropriately sized and operated, mainly because of the intermittency of the solar energy, to deliver heat at reasonable cost while preventing any conflict of usage between various heat producers: Combined Heat and Power (CHP), biomass boiler, solar thermal energy, etc. Exergy analysis is a promising tool to tackle this issue. To progress in that direction, this paper presents a dynamic exergoeconomic analysis on an existing solar district heating (SDH) located in the North West of France in which conflict of usage occurs. The actual configuration is implemented in Dymola and includes a large-scale solar field, a biomass boiler, a gas boiler and a thermal energy storage. Based on models available in Modelica Buildings Library, an exergoeconomic approach (Specific Exergy Costing) is implemented. Field data from year 2019 are used as input to model the demand and solar data are taken from SoDa Service. Two cases are considered: one without the solar field (reference case), and one with the solar field. This study demonstrates that adding a solar field in an existing district heating system leads to a degradation from an exergy point of view. This degradation mainly occurs during the non-heating season, when the solar energy is the source of $26 \%$ of the overall exergy destruction. It is shown that with the solar field the specific cost of the heat increases by $10 \%$ during the non-heating season. The study highlights that adding a solar field reduces the operating time of the boilers and thus increases their investment cost rates. Moreover, the solar field is the main source of extra cost, which degrades the system for an exergoeconomic point of view.
\end{abstract}

\section{Keywords}

Dynamic exergoeconomic analysis; Dynamic modelling and simulation; Modelica; Solar District Heating.

\section{Introduction}

District heating $(\mathrm{DH})$ systems are an important technology to address sustainability in modern cities. To increase the renewable share in DH networks as required by the European Directive 2012/27 the integration of solar thermal heat is seen as promising. Winterscheid et al. [1] presented a methodology of including solar energy in the sub-network of an existing district heating supplied by a large CHP facility and demonstrated that this integration brings benefits in $\mathrm{CO}_{2}$ emission reduction and operation flexibility. Carpaneto et al. [2] developed an optimization procedure based of operating cost to define the dispatching strategy for solar collectors and other heat producers present in a network and highlighted the reduction of the operating cost during mid-season periods and summer with the integration of solar energy.

$\mathrm{Li}$ and Svendsen [3] have highlighted the usefulness of using exergy analysis for DH performance evaluation. However, this analysis does not take into account the costs associated to fuel and investment. In order to go further an exergoeconomic analysis is needed. For instance, Alkan et al. [4] conducted an exergoeconomic analysis of a geothermal district heating system a using the SPECO (specific exergy costing) approach. This method is developed by Lazzaretto and Tsatsaronis [3] and allows to define fuel and product for each component and to calculate the associated costs. Torío and Schmidt [5] have stressed out that, as DH networks operate at temperatures close to the reference environment, their performances are strongly influenced by the dynamic behaviour of both the system and the outdoor air conditions. Hence, dynamic exergy analysis is mandatory to conduct a fully relevant 
exergoeconomic analysis on $\mathrm{DH}$. This approach has been successfully used by Meesenburg et al. [6] for a heat pump system and by Sayadi et al. in a building application [7].

The present work aims at using a dynamic exergoeconomic approach to assess the impact of the integration of solar energy in an existing DH system, located in the North West of France, on the performances of other heat producers. After a presentation of the case study, the method, the exergy and exergoeconomic models are described. Then the results of the simulation over one year are presented and the impacts of the integration of the solar field from energy, exergy and exergoeconomic points of view are discussed. Finally, conclusions are presented.

\section{Chateaubriant solar district heating description}

\subsection{General overview}

The case under consideration is an existing solar district heating system in the North West of France, in the city of Chateaubriant. A simplified layout of the DH is presented in Fig. 1. It consists of two branches (North and South) for a total annual heat demand of $18.6 \mathrm{GWh}$, for both space heating and domestic hot water. The flows of the South and North branches are mixed before entering the boiler room which comprises a gas boiler and a biomass boiler. In 2018 a solar thermal field was added on the Northern branch, preheating the return of that branch. It is composed of 200 flat-plate collectors (model K5Giga+ from KBB brand), inclined $30^{\circ}$ to the horizontal, 146 facing south and 54 facing $7^{\circ}$ southeast. The solar loop is filled with monopropylene glycol (MPG) at $33 \%$ to protect the solar field against frost damage. The secondary circuit contains the secondary pump and a storage made of three stratified storage tanks connected in series. The solar loop is separated from the secondary circuit by a heat-exchanger with a yearly mean efficiency of 0.69 . Table 1 summarizes the main values of the design parameters of the studied system. A CHP also exists but was not considered in the present case for the sake of simplicity, as its operation depends on specific electricity contracts.

The heat demand profile of the district heating for the year 2019 is shown in Fig. 2. The daily mean temperature and the number of hours per day with solar irradiation higher than $350 \mathrm{~W} / \mathrm{m}^{2}$, which is the usual value of solar irradiation for which the pump of the solar loop turns on in the case studied, are presented in Fig. 3.

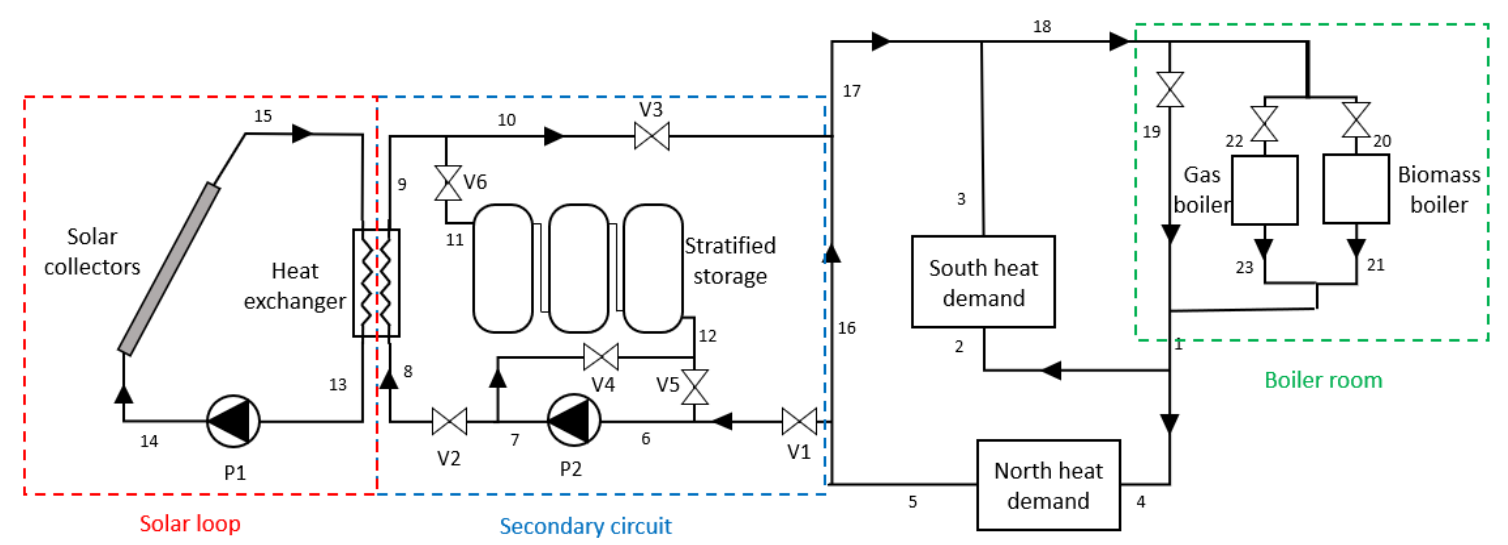

Fig. 1. Schematic of the solar district heating of Chateaubriant

Table 1. Technical data of the $S D H^{1}$

\begin{tabular}{ll}
\hline P1 efficiency & 0.45 \\
P2 efficiency & 0.58 \\
Heat exchanger effectiveness & 0.69 \\
Gas boiler efficiency & 0.658 \\
Biomass boiler efficiency & 0.845 \\
Gas boiler nominal capacity & $6 \mathrm{MW}$ \\
Biomass boiler nominal capacity & $3 \mathrm{MW}$ \\
Biomass boiler minimal capacity & $750 \mathrm{~kW}$ \\
Solar field nominal capacity (aperture area) & $1.7 \mathrm{MW}\left(2340 \mathrm{~m}^{2}\right)$ \\
Thermal storage tank capacity & $3 \times 50 \mathrm{~m}^{3}$ \\
\hline
\end{tabular}

${ }^{1}$ Data provided by Chateaubriant $\mathrm{DH}$ operator Cofely thanks to Cylergie 


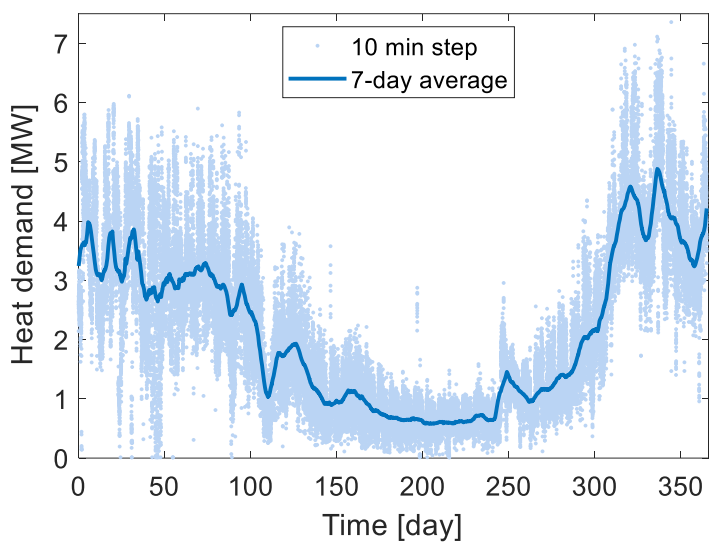

Fig. 2. Heat demand profile during the year 2019

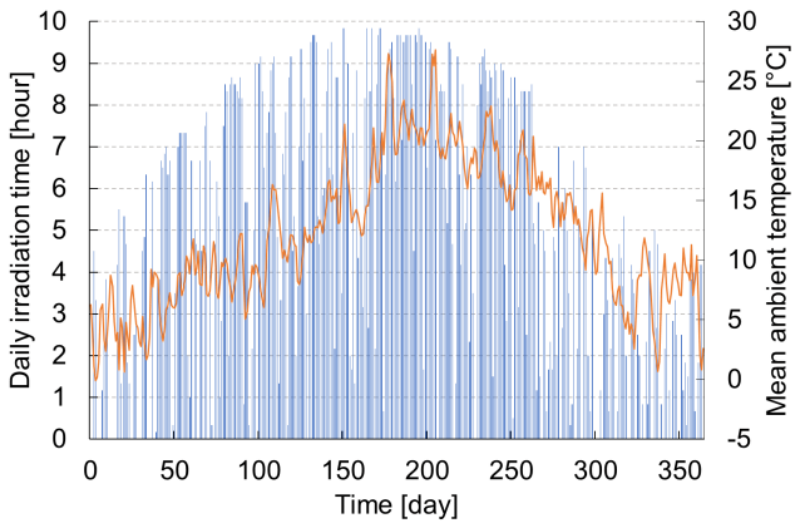

Fig. 3. Number of hours per day with solar irradiation higher than $350 \mathrm{~W} / \mathrm{m}^{2}$ and daily mean ambient temperature of Chateaubriant SDH for year 2019

\subsection{Control strategy}

The control unit manages the solar field system by operating pumps and valves. A rise time of ten minutes for the pumps and five minutes for the valves is assumed. Pump P1 is switched on using an irradiation threshold equal to four times the north return-flow temperature. Pump P2 and the valves are controlled in order to switch between three main operation modes:

1. Direct mode, the solar heat collected is directly transferred to the district network.

2. Charging mode, the solar heat collected is stored in the stratified storage tank.

3. Discharging mode, the heat stored in the stratified storage tank is discharged in the network, with adjusted flow rate depending in the demand and the temperature at the top of the storage tank.

Furthermore, an antifreeze mode is activated when outlet temperature of the collectors is below $5^{\circ} \mathrm{C}$ in order to avoid the freeze of water in the secondary loop. To prevent overheating in the solar loop, the direct mode is launched when this temperature exceeds $130^{\circ} \mathrm{C}$ and a storage fully charged. The switch from one mode to another depends on the outlet temperature of the collectors, return temperature and storage tank temperatures. The positions of the valves V1 to V6 and the state of the pump P2 for each mode are reported in Table 2 . The supply temperature is calculated using a heating curve based on the ambient temperature. In the boiler room the needed heat load is calculated comparing the set temperature with the boiler room inlet temperature and the mass flow rate. The priority is given to the solar field, as it preheats the return of the Northern branch, and then to the biomass boiler. The gas boiler is turned on only if the heat load needed at the boiler room inlet is lower than the minimal capacity of the biomass boiler or higher than the maximum capacity of the biomass boiler.

Table 2. P2 state and valves positions for the different operating modes

\begin{tabular}{lll}
\hline Operating mode & P2 state & Valves position \\
& On $1, \mathrm{~V} 2, \mathrm{~V} 3, \mathrm{~V} 4, \mathrm{~V} 5, \mathrm{~V} 6\}$ \\
\hline Direct & On & $\{1,1,1,0,0,0\}$ \\
Charging & On & $\{0,1,0,0,1,1\}$ \\
Discharging & Off & $\{1,0,1,1,0,1\}$ \\
Rest & On & $\{0,0,0,0,0,0\}$ \\
Antifreeze & On & $\{1,1,1,0,0,0\}$ \\
Overheating & & $\{1,1,1,0,0,0\}$ \\
\hline
\end{tabular}

\section{Model}

It was chosen to develop the model using the Modelica language and to implement it in Dymola@. When relevant, existing libraries were used and, in all cases, exergo-economic model was developed for each sub-component and for the whole system.

Demand side modelling. The aim of the work being focused on the heat generation and storage systems, it was decided to not model into details the distribution network. Hence, the heat demand model of each 
branch is a simplified model of the demand side of the system. It is composed of a supply and a return pipe of $2.5 \mathrm{~km}$ each and a component extracting thermal energy from the fluid according to the heat demand. 10 min data gathered by the DH operator (Cofely) for year 2019 are used as input.

Heat producers model. The model contains two main lumped models: the solar field model, gathering the solar loop and the secondary circuit, and the boiler room model which is composed of the gas boiler and the biomass boiler. Solar collector model and stratified storage model are described in section 3.2. and 3.3. For the other components, the model used are listed in Table 3.

The ambient temperature and the solar radiation are delivered by the SoDa service [8] and derive from the MERRA-2 dataset [9] and the HelioClim-3 database [10], both with a time step of 10 min and for year 2019.

Table 3. Existing models used for the heat producers

\begin{tabular}{lll}
\hline Component & Library & Model \\
\hline Valve & Modelica Standard Library & Valvelncompressible \\
Pump & Modelica Buildings Library & FlowControlled_m_flow \\
Heat exchanger & Modelica Buildings Library & ConstantEffectiveness \\
Boiler & Modelica Buildings Library & PrescribedOutlet \\
Water & Modelica Standard Library & Simple liquid water medium \\
\hline
\end{tabular}

\subsection{Exergoeconomic model}

\subsubsection{Reference environment}

To conduct an exergy analysis, a reference state must be defined. The properties of this reference state should be constant during and after the interaction with the system studied. However, in this present study the ambient temperature fluctuates through the year of simulation. As the reference temperature has to be the most favourable for the process studied, Pons [11] proposed to choose the mean ambient temperature over the time horizon. Thus, the annual mean ambient temperature $\left(T_{0}=12.25^{\circ} \mathrm{C}\right)$ at atmospheric pressure ( $p_{0}=1.013$ bar) was chosen.

\subsubsection{Exergy}

According to [12] the exergy balance for a control volume can be written as:

$$
\frac{d E x}{d t}=\sum_{i} \dot{E} x_{i}-\sum_{o} \dot{E} x_{o}+\sum_{j}\left(1-\frac{T_{0}}{T_{j}}\right) \cdot \dot{Q_{J}}+\dot{W}-\dot{E} x_{D}
$$

where the term $\frac{d E x}{d t}$ represents the variation on the control volume, $E x_{D}$ denotes the exergy destruction within the control volume, $\dot{E} x_{i}$ and $\dot{E} x_{o}$ represents the exergy flow at the inlet and outlet of the control volume, $\dot{Q}_{j}$ is the heat flow crossing the boundary of the control volume at absolute temperature $T_{j}$ and $\dot{W}$ is the power. The exergy content of a material stream is evaluated as:

$$
\dot{E x_{i / o}}=\dot{m}_{i / o} \cdot e x_{i / o}=\dot{m}_{i / o} \cdot\left[\left(h_{i / o}-h_{0}\right)-T_{0}\left(s_{i / o}-s_{0}\right)\right]
$$

where the subscript zero indicates properties at the reference state. It is assumed that there is no chemical reaction in the studied system.

For the exergy analysis, fuel and product are defined both for each component and for the whole system, based on their function and purpose at each time step on the simulation. The expressions obtained are presented in Table 4. With these definitions, the exergy balance for a system or an individual component is:

$$
E \dot{x}_{D}=E \dot{x}_{F}-E \dot{x}_{P}
$$

Furthermore, the exergy efficiency is defined as: 


$$
\eta_{e x}=\frac{E \dot{x}_{P}}{E \dot{x}_{F}}=1-\frac{E \dot{x}_{D}}{E \dot{x}_{F}}
$$

Table 4. Definitions of fuel and product exergies of each component. Charging and discharging refer to charging/discharging of the storage tank.

\begin{tabular}{|c|c|c|}
\hline Component & Fuel exergy $E \dot{x}_{F}$ & Product exergy $E \dot{x}_{P}$ \\
\hline Solar collectors & $A_{p} \cdot I_{p} \cdot\left(1-\frac{4}{3} \frac{T_{0}}{T_{\text {sun }}}\right)$ & $E x_{15}-E x_{14}$ \\
\hline Heat exchanger & $E x_{15}-E x_{16}$ & $\dot{E x_{9}}-\dot{E x_{8}}$ \\
\hline Gas boiler & $\dot{m}_{\text {fuel,gas }} \cdot L H V_{\text {fuel,gas }}$ & $\dot{E} x_{23}-\dot{E} x_{22}$ \\
\hline Biomass boiler & $\dot{m}_{\text {fuel,biomass }} \cdot L H V_{\text {fuel,biomass }}$ & $E x_{21}-E x_{20}$ \\
\hline Pump 1 & $\dot{W}_{P 1}$ & $E x_{14}-E x_{13}$ \\
\hline Pump 2 & $\dot{W}_{P 2}$ & $\dot{E x_{7}}-\dot{E x_{6}}$ \\
\hline Stratified storage tank & $\left\{\begin{array}{l}E x_{11}-E x_{12}: \text { charging } \\
\left|\frac{d E x_{\operatorname{tank}}}{d t}\right|: \text { discharging }\end{array}\right.$ & $\left\{\begin{array}{c}\frac{d E x_{\text {tank }}}{d t}: \text { charging } \\
E x_{11}-E x_{12}: \text { discharging }\end{array}\right.$ \\
\hline
\end{tabular}

The expression of the solar exergy is the coming from the approach described by Spanner in [13], where $T_{\text {sun }}$ represents the equivalent temperature of the sun. In this study a value of $5780 \mathrm{~K}$ is assumed.

\subsubsection{Exergoeconomy}

To conduct an exergoeconomic analysis, a cost is assigned to all of the exergy streams. In the present study the SPECO method [14] is used for exergy costing. A specific cost $c_{i}$ is assigned to each exergy stream $E x_{i}$ associated with the cost stream $\dot{C}_{i}$ :

$$
\dot{C}_{i}=c_{i} \cdot \dot{E} x_{i} .
$$

In order to calculate the specific cost of each stream, a dynamic cost balance is formulated for each component:

$$
\frac{d C}{d t}=\sum_{\substack{\text { material } \\ \text { stream }}} \dot{C}_{i}+\sum_{k} c_{e l} \cdot \dot{W}_{k}+\dot{Z} .
$$

$\dot{Z}$, the annualised capital cost of the component, depending on the interest rate $i$ and equipment lifetime $n$ is determined as:

$$
\dot{Z}=\frac{Z \cdot \frac{i \cdot(1+i)^{n}}{(1+i)^{n}-1}}{t_{o p}}
$$

where $t_{\mathrm{op}}$ is the operating time of the component over the entire time period of the study, and can be expressed in any unit of time. If in hours, $\dot{Z}$ will be in $€ / h$.

For each component, the cost product can be calculated with the cost balance as follows: 


$$
c_{P} \cdot \dot{E} x_{P}=c_{F} \cdot \dot{E} x_{F}+\dot{Z} .
$$

All cost balance equations and auxiliary equations are summarized in Table 5. For some components where the number of exit streams is larger than 1 the F-rule or P-rule are applied to complete the mathematical calculation [14]. Specific costs of the streams coming for sub-stations are assumed to be zero and specific cost of the solar heat too.

Table 6 presents the economic data of the system.

Table 5. Cost balance and auxiliary equations for each component

\begin{tabular}{lll}
\hline Component & Cost rate balance & Auxiliary equation \\
\hline Solar collectors & $\dot{C}_{15}-\dot{C}_{14}=\dot{C}_{\text {sun }}+\dot{Z}_{\text {coll }}$ & $c_{\text {sun }}=0$ \\
Heat exchanger & $\dot{C}_{9}-\dot{C}_{8}=\dot{C}_{15}-\dot{C}_{13}+\dot{Z}_{H X}$ & $c_{13}=c_{15}$ \\
Pump 1 & $\dot{C}_{14}-\dot{C}_{13}=\dot{C}_{W, P 1}+\dot{Z}_{P 1}$ & $/$ \\
Pump 2 & $\dot{C}_{7}-\dot{C}_{6}=\dot{C}_{W, P 2}+\dot{Z}_{P 2}$ & \\
Storage tank & $\left\{\begin{array}{c}d C_{\text {tank }} \\
d t\end{array}=\dot{C}_{11}-\dot{C}_{12}+\dot{Z}_{\text {tank }}\right.$ : charging \\
$\dot{C}_{11}-\dot{C}_{12}=c_{\text {tank }} \cdot\left|\frac{d E x_{\text {tank }}}{d t}\right|:$ discharging & $c_{12}=0$ if discharge \\
Biomass boiler & $\dot{C}_{21}-\dot{C}_{20}=\dot{C}_{\text {fuel,gas }}+\dot{Z}_{\text {biomass }}$ & $/$ \\
Gas boiler & $\dot{C}_{23}-\dot{C}_{22}=\dot{C}_{\text {fuel, biomass }}+\dot{Z}_{\text {gas }}$ & $/$
\end{tabular}

Table 6. Economic data

\begin{tabular}{ll}
\hline Parameter & Value \\
\hline Cost of electricity [€/kWh] & 0.14 \\
Cost of gas [€/kWh] & 0.039 \\
Cost of biomass [€/kWh] & 0.023 \\
Gas boiler investment cost [M€] & 1.20 \\
Biomass boiler investment cost [M€] & 2.10 \\
Solar collector field investment cost [M€] & 1.35 \\
Lifetime of all components except gas boiler [year] & 20 \\
Gas boiler lifetime [year] & 25 \\
Interest rate [\%] & 3.75 \\
\hline
\end{tabular}

The SPECO method allows to determine the cost of exergy destruction in each component of a system, by evaluating this cost as a cost for spent extra fuel [14]:

$$
\dot{C}_{D}=c_{F} \cdot E x_{D} \text { when } \dot{E} x_{P} \text { is fixed }
$$

Two metrics are often used in the exergoeconomic analysis. The relative cost difference, defined by Eq. (10), represents the part of the cost due to exergy destruction and investment:

$$
r=\frac{c_{P}-c_{F}}{c_{F}}
$$

The exergoeconomic factor expresses the ratio of the investment cost to the total cost:

$$
f=\frac{\dot{Z}}{\dot{Z}+c_{F} \cdot \dot{E} x_{D}}
$$




\subsection{Solar collectors' model}

The solar collectors' model is based on that proposed by Osorio \& Carvalho [15] according to the European Standard EN 12975. The heat balance can be written as:

$$
\frac{\dot{Q}_{\text {coll }}(\theta)}{A_{p}}=\eta_{0} \cdot I_{p}(\theta)-a_{1} \cdot\left(T_{\text {mean }}-T_{\text {amb }}\right)-a_{2} \cdot\left(T_{\text {mean }}-T_{\text {amb }}\right)^{2}-c_{\text {eff }} \cdot \frac{d T_{\text {mean }}}{d t}
$$

where $T_{\text {mean }}$ is the mean fluid temperature of the collectors defined as:

$$
T_{\text {mean }}=\frac{T_{\text {in }}+T_{\text {out }}}{2}
$$

$I_{p}(\theta)$ is the solar radiation received by the collectors at the incident angle $\theta \cdot I_{p}(\theta)$ is the sum of the direct and diffuse component of solar radiation, both multiplied by the corresponding incidence angle modifier:

$$
I_{p}(\theta)=K_{b}(\theta) \cdot G_{b}+K_{d} \cdot G_{d} .
$$

\subsection{Stratified storage tank}

\subsubsection{Energy model}

The stratified storage tank model is adapted from the Stratified model available in the Modelica Buildings Library. Three tanks are connected in series. Each of them is divided into 30 layers from top to bottom. For each layer dynamic mass and energy balances are solved. The fluid is assumed to be ideally mixed inside each layer. Heat losses to the environment are taken into account.

\subsubsection{Exergy model}

According to Eq. (1) the exergy balance for the stratified storage tank can be written as:

$$
\frac{d E x_{\text {tank }}}{d t}=\dot{E} x_{\text {in }}-\dot{E} x_{\text {out }}-\dot{E} x_{D}
$$

where $E x_{\text {tank }}$ is the stored exergy. $E x_{\text {tank }}$ is evaluated as the sum of the exergy stored in each layer:

$$
E x_{\text {tank }}=\sum_{i=1}^{N_{\text {layers }}} m_{i} \cdot e x_{i}
$$

where $m_{i}$ is the mass and $e_{i}$ the specific exergy of layer $i$. Assuming that the water in the tank behaves as an ideal liquid, the specific exergy of every layer can be evaluated from temperatures calculated from the exergy balance of each layer [16] :

$$
e x_{i}=c_{p, w} \cdot\left[\left(T_{i}-T_{0}\right)-T_{0} \cdot \ln \left(\frac{T_{i}}{T_{0}}\right)\right]
$$

During the simulation, the purpose of the stratified storage tank changes. Hence expressions of fuel exergy and product exergy depend on its state. During charging, the fuel exergy is defined as the exergy of the hot water entering at the top of the tank minus the exergy of the outflow at the bottom. The exergy product is then the increase of stored exergy in the tank $E x_{\text {tank }}$. During discharging, the purpose of the tank is to deliver heat to the fluid. Thus, the fuel is the heat previously stored. When the stratified storage tank is neither charging nor discharging, product and fuel are not defined, the decrease of exergy due to heat losses to environment corresponds to exergy destruction:

$$
E x_{D}=\left|\frac{d E x_{\text {tank }}}{d t}\right|
$$

\subsubsection{Exergoeconomic model}

As for energy, a cost is accumulated within the component during charging. The dynamic cost balance is:

$$
\frac{d C_{t a n k}}{d t}=\dot{C}_{11}-\dot{C}_{12}+\dot{Z}_{\text {tank }}
$$

where $C_{\text {tank }}$ denotes the accumulated cost, i.e. the monetary value of the stored energy. The operating time $t_{\mathrm{op}}$ of the thermal storage is assumed to be the cumulating charging time. The integration of Eq. (19) over the whole charging period gives the final value, $C_{\text {tank }}$, of the heat stored during this period. If the tank was already partly loaded before charging, the value of this residual heat has to be added to 
$C_{\text {tank }}$ to obtained a consolidated value of the heat in the tank. The specific cost assigned to the exergy contained in the tank after charging is then calculated as:

$$
c_{\text {tank }}\left(t_{\text {end }}\right)=\frac{1}{E x_{\text {tank }}\left(t_{\text {end }}\right)} \cdot\left[\int_{t_{\text {start }}}^{t_{\text {end }}} \frac{d C_{\text {tank }}}{d t} \cdot d t+c_{\text {tank }}\left(t_{\text {start }}\right) \cdot E x_{\text {tank }}\left(t_{\text {start }}\right)\right]
$$

where $c_{\text {tank }}\left(t_{\text {start }}\right)$ is the specific cost evaluated after the previous load. When discharging, the product is the heat exiting the stratified storage tank and the fuel, the heat stored. Thus, the dynamic cost balance is formulated as:

$$
\dot{C}_{11}-\dot{C}_{12}=c_{\text {tank }}\left(t_{\text {end }}\right) \cdot\left|\frac{d E x_{\text {tank }}}{d t}\right|
$$

where $c_{\text {tank }}$ is the specific cost of the stored exergy calculated after charging by Eq. (20). The investment cost rate is already contained in the specific cost $c_{\text {tank }}$, so that it is not again taken into account in Eq. (21) to avoid counting it twice.

With the assumption that $c_{12}=0$, Eq. (22) can be written as:

$$
c_{11}=\frac{c_{\text {tank }}\left(t_{\text {end }}\right)}{E x_{11}} \cdot\left|\frac{d E x_{\text {tank }}(t)}{d t}\right|
$$

\section{Results}

To compare the performance of the system with and without the solar field, both cases are simulated over one year with the same input data. Energy, exergy and exergoeconomic analysis are then carried out. In order to facilitate the analysis of the results two periods of time are defined: the heating season, from October $15^{\text {th }}$ to April $14^{\text {th }}$, and the non-heating season, from April $15^{\text {th }}$ to October $14^{\text {th }}$. For the determination of average values associated with one of the heating units, the values of only the periods when the respective equipment is operating are considered. Results are presented in Table 7.

\begin{tabular}{|c|c|c|c|c|c|c|c|c|}
\hline & \multicolumn{3}{|c|}{ Reference case } & \multicolumn{4}{|c|}{ Solar case } \\
\hline & & $\begin{array}{l}\text { Total } \\
\text { system }\end{array}$ & Gas & Biomass & $\begin{array}{l}\text { Total } \\
\text { system }\end{array}$ & Gas & Biomass & $\begin{array}{l}\text { Solar } \\
\text { field }\end{array}$ \\
\hline \multirow{19}{*}{$\begin{array}{l}\text { Overall } \\
\text { year }\end{array}$} & $\dot{\mathrm{Z}} \quad[€ / \mathrm{h}]$ & 26.51 & 15.94 & 21.85 & 37.35 & 15.81 & 23.34 & 63.70 \\
\hline & $t_{o p}[h]$ & 8760 & 4568 & 6763 & 8760 & 4606 & 6330 & 1525 \\
\hline & $t_{\text {op,fullLoad }}[\mathrm{h}]$ & 1 & I & 2743 & / & I & 2708 & 1 \\
\hline & $\begin{array}{l}\text { Energy } \\
\text { coverage [\%] }\end{array}$ & 100 & 21 & 79 & 100 & 20 & 75 & 5 \\
\hline & $\dot{Q}_{\text {mean }}[\mathrm{kW}]$ & I & 855 & 2192 & I & 820 & 2247 & 615 \\
\hline & $\dot{Q}_{s d}$ & / & 639 & 825 & I & 655 & 804 & 312 \\
\hline & $E x_{D}[G W h]$ & 19.8 & 5.1 & 14.7 & 21.3 & 4.9 & 14.1 & 2.3 \\
\hline & $E x_{D, \text { mean }}[\mathrm{kW}]$ & 2266 & 1114 & 2175 & 2433 & 1062 & 2230 & 1168 \\
\hline & $\dot{E} x_{D, s d}$ & 1588 & 857 & 819 & 1538 & 877 & 797 & 484 \\
\hline & $\eta_{\text {ex,mean }}[\%]$ & 15.0 & 12.7 & 16.1 & 14.1 & 12.7 & 16.1 & 7.8 \\
\hline & $\eta_{e x, s d}$ & 1.5 & 0.9 & 2.2 & 2.5 & 0.8 & 0.4 & 3.1 \\
\hline & $\dot{C}_{D, \text { mean }}[€ / \mathrm{h}]$ & 61.5 & 29.9 & 49.6 & 61.6 & 29.1 & 50.8 & 3.3 \\
\hline & $\dot{C}_{D, s d}$ & 46.8 & 33.4 & 20.0 & 50.1 & 34.0 & 19.6 & 34.8 \\
\hline & $\begin{array}{l}c_{P, \text { mean }} \\
{[€ / \mathrm{kWh}]}\end{array}$ & 0.31 & 0.66 & 0.21 & 0.35 & 0.66 & 0.21 & 0.74 \\
\hline & $c_{P, s d}$ & 0.17 & 1.40 & 0.21 & 0.68 & 1.27 & 0.13 & 0.74 \\
\hline & $r_{\text {mean }}$ & 9.71 & 15.99 & 8.13 & 20.96 & 16.16 & 8.11 & 633.35 \\
\hline & $r_{s d}$ & 3.33 & 36.18 & 9.05 & 43.80 & 32.97 & 5.48 & 200.47 \\
\hline & $f_{\text {mean }}$ & 0.370 & 0.541 & 0.330 & 0.469 & 0.546 & 0.337 & 0.274 \\
\hline & $f_{s d}$ & 0.144 & 0.331 & 0.108 & 0.191 & 0.326 & 0.106 & 0.175 \\
\hline \multirow{4}{*}{$\begin{array}{l}\text { Non- } \\
\text { heating } \\
\text { season }\end{array}$} & $t_{o p}[\mathrm{~h}]$ & 4392 & 1963 & 2451 & 4392 & 1955 & 2108 & 1062 \\
\hline & $t_{\text {op,fullLoad }}[\mathrm{h}]$ & / & / & 36 & I & I & 36 & I \\
\hline & $\begin{array}{l}\text { Energy } \\
\text { coverage [\%] }\end{array}$ & 100 & 25 & 75 & 100 & 21 & 64 & 15 \\
\hline & $\dot{Q}_{\text {mean }}[\mathrm{kW}]$ & I & 574 & 1360 & I & 508 & 1405 & 658 \\
\hline
\end{tabular}

Table 7. Energy, exergy and exergoeconomic results of the whole system and each component in the two cases studied. 


\begin{tabular}{|c|c|c|c|c|c|c|c|c|}
\hline & $\dot{Q}_{s d}$ & I & 139 & 517 & I & 181 & 526 & 320 \\
\hline & $E x_{D}[\mathrm{GWh}]$ & 4.8 & 1.5 & 3.3 & 5.8 & 1.3 & 2.9 & 1.5 \\
\hline & $\dot{E} x_{D, \text { mean }}[\mathrm{kW}]$ & 1096 & 760 & 1349 & 1322 & 665 & 1395 & 1235 \\
\hline & $E x_{D, s d}$ & 507 & 190 & 512 & 571 & 253 & 520 & 471 \\
\hline & $\eta_{\text {ex,mean }}[\%]$ & 14.5 & 12.7 & 16.0 & 13.2 & 12.7 & 16.1 & 8.3 \\
\hline & $\eta_{e x, s d}$ & 1.8 & 0.9 & 3.3 & 2.7 & 0.8 & 0.4 & 3.3 \\
\hline & $\dot{C}_{D, \text { mean }}[€ / \mathrm{h}]$ & 30.7 & 18.1 & 29.9 & 55.8 & 16.3 & 30.9 & 1.5 \\
\hline & $\dot{C}_{D, s d}$ & 10.6 & 15.4 & 13.4 & 41.9 & 14.5 & 13.6 & 0.6 \\
\hline & $\begin{array}{l}c_{P, \text { mean }} \\
{[€ / \mathrm{kWh}]}\end{array}$ & 0.40 & 0.59 & 0.25 & 0.45 & 0.63 & 0.25 & 0.70 \\
\hline & $c_{P, s d}$ & 0.18 & 1.23 & 0.31 & 0.91 & 1.09 & 0.20 & 0.84 \\
\hline & $r_{\text {mean }}$ & 11.80 & 14.26 & 9.70 & 32.20 & 15.45 & 9.67 & 408.67 \\
\hline & $r_{s d}$ & 3.06 & 31.99 & 13.33 & 58.20 & 28.17 & 8.61 & 155.73 \\
\hline & $f_{\text {mean }}$ & 0.478 & 0.608 & 0.433 & 0.603 & 0.625 & 0.441 & 0.270 \\
\hline & $f_{s d}$ & 0.080 & 0.314 & 0.097 & 0.140 & 0.301 & 0.098 & 0.314 \\
\hline \multirow{18}{*}{$\begin{array}{l}\text { Heating } \\
\text { season }\end{array}$} & $t_{o p}[\mathrm{~h}]$ & 4368 & 2605 & 4312 & 4368 & 2651 & 4222 & 464 \\
\hline & \multirow{2}{*}{$\begin{array}{l}t_{\text {op,fullLoad }}[\mathrm{h}] \\
\text { Energy } \\
\text { coverage [\%] }\end{array}$} & l & l & 2707 & l & l & 2672 & I \\
\hline & & 100 & 19 & 81 & 100 & 19 & 79 & 2 \\
\hline & $\dot{Q}_{\text {mean }}[\mathrm{kW}]$ & l & 1073 & 2665 & l & 1053 & 2668 & 515 \\
\hline & $\dot{Q}_{s d}$ & / & 774 & 547 & l & 773 & 547 & 265 \\
\hline & $E x_{D}[\mathrm{GWh}]$ & 15.0 & 3.6 & 11.4 & 15.5 & 3.6 & 11.2 & 0.7 \\
\hline & $\dot{E} x_{D, \text { mean }}[\mathrm{kW}]$ & 3438 & 1381 & 2644 & 3547 & 1354 & 2647 & 1043 \\
\hline & $E x_{D, s d}$ & 1432 & 1045 & 542 & 1389 & 1042 & 543 & 484 \\
\hline & $\eta_{\text {ex,mean }}[\%]$ & 15.5 & 12.7 & 16.2 & 15.0 & 12.7 & 16.2 & 6.6 \\
\hline & $\eta_{e x, s d}$ & 0.8 & 0.8 & 0.8 & 1.4 & 0.8 & 0.5 & 2.0 \\
\hline & $\dot{C}_{D, \text { mean }}[€ / \mathrm{h}]$ & 92.5 & 40.9 & 61.3 & 65.7 & 40.6 & 61.2 & 4.0 \\
\hline & $\dot{C}_{D, s d}$ & 48.6 & 41.9 & 12.8 & 57.2 & 41.6 & 13.5 & 20.6 \\
\hline & $\begin{array}{l}c_{P, \text { mean }} \\
{[€ / \mathrm{kWh}]}\end{array}$ & 0.22 & 0.71 & 0.19 & 0.24 & 0.68 & 0.19 & 0.83 \\
\hline & $c_{P, s d}$ & 0.09 & 1.50 & 0.12 & 0.29 & 1.39 & 0.06 & 0.28 \\
\hline & $r_{\text {mean }}$ & 7.62 & 17.28 & 7.23 & 9.69 & 16.68 & 7.33 & 653.26 \\
\hline & $r_{s d}$ & 2.00 & 38.97 & 5.01 & 13.87 & 36.08 & 2.48 & 195.77 \\
\hline & $f_{\text {mean }}$ & 0.261 & 0.478 & 0.272 & 0.334 & 0.475 & 0.284 & 0.282 \\
\hline & $f_{s d}$ & 0.107 & 0.334 & 0.059 & 0.130 & 0.331 & 0.062 & 0.068 \\
\hline
\end{tabular}

\subsection{Energy analysis}

\subsubsection{Reference case}

In the reference case the biomass boiler operates 6,763 hours, including 2,743 hours on full load, for an energy coverage rate of $81 \%$ during the heating season and $75 \%$ during the non-heating season. During the non-heating, when the heat demand is for domestic hot water only, the mean heat flow delivered by the biomass and the gas boiler are respectively 1,360 and $573 \mathrm{~kW}$ whereas during heating season these values are higher: 2,665 for the biomass and 1,073 for the gas boiler. During heating season, gas boiler operates simultaneously with the biomass during $95 \%$ of its operating time, while only during $1.4 \%$ during the non-heating season. These results highlight two different behaviours of the gas boiler. During the non-heating season, the gas boiler operates when the heat demand is lower than the biomass minimal capacity, mainly during daytime, whereas during heating season it acts as a complement to the biomass, when heat demand is higher than the biomass maximum capacity.

\subsubsection{Comparison of the two cases}

With the integration of the solar field, the annual heat delivered by the biomass boiler decreases from 14.8 to $14.2 \mathrm{GWh}$ and its operating time decreases by $6.4 \%$. The solar field operates 1,525 hours during the year (70\% during non-heating season, 30\% during heating season), hence having a main impact during the non-heating season.

During this period, the energy coverage ratio falls from $75 \%$ to $64 \%$ for the biomass, with an operating time $14 \%$ lower, and from $25 \%$ to $21 \%$ for the gas boiler with no significant variation of the operating time. This is due to the operation of the solar field during $24 \%$ of the time in direct or discharging mode 
resulting in an energy coverage of $15 \%$. Two cases can occur during solar filed operation: first, the heat delivered by the solar field meets the total heat demand so that none of the two boilers operates $(32 \%$ of the operating time). Second, the heat delivered only preheats the water before the boiler room. However, the remaining heating load needed to complete the heat demand is lower than the biomass minimum capacity so that the biomass boiler cannot be used and the gas boiler has to be switched on.

For the heating season, the impact of the solar field is less significant (464 hours of operation for an energy coverage of $2 \%$ ). In consequence, both energy coverage and operating time of the gas and biomass boiler are mainly unchanged compared to the reference case.

\subsection{Exergy analysis}

\subsubsection{Reference case}

In both boilers the exergy destruction and the mean exergy destruction rate are higher during heating season than during the non-heating season. This is because of a higher operating time and a higher heating load during the heating season. Unlike the gas boiler, the exergy efficiency of the biomass boiler depends on the period of the year: it is $1.3 \%$ higher during the heating season than during the nonheating season. It is due to a lower temperature difference between the inlet and the outlet of the biomass boiler, because of a lower supply temperature and a inlet fluid pre-heated by the solar field, in non-heating season than in heating season

\subsubsection{Comparison of the two cases}

With the integration of the solar field the overall exergy destruction increases by $7 \%$ (21\% in non-heating season, $3 \%$ in heating season). The reason is the large contribution of the solar field to the overall exergy destruction. In addition to this increase, the overall exergy efficiency decreases by $9 \%$ during the non-heating season and by $3 \%$ during heating season. The cause is the exergy efficiency lower than $9 \%$ for the solar field. Hence, the integration of the solar field degrades the performances of the system from an exergy point of view. Considering the two boilers, the slight decreases of their exergy destruction, both by $4 \%$, can be explained by the reduction of their operating time. The integration of the solar field does not impact the exergy efficiency of the gas boiler both during heating and non-heating season. However, it reduces the exergy efficiency of the biomass from $17 \%$ to $16 \%$ during the nonheating season and does not impact it during the heating-season. The significant drop of the mean exergy destruction flow rate in the gas boiler during the non-heating season with the integration of the solar field is linked to its use at a lower capacity. Similarly, the rise by $3 \%$ of the exergy destruction flow rate in the biomass is caused by a use at a higher capacity.

Hence, the integration of the solar field degrades the performances of the system from an exergy point of view. The performances of the gas boiler are not impacted whereas the biomass boiler is less exergy efficient on a yearly basis.

\subsection{Exergoeconomic analysis}

\subsubsection{Reference case}

In the reference case, an analysis of the relative cost difference shows that the system is more exergoeconomic efficient during the heating season. With a mean exergoeconomic factor of 0.261 during this period, the exergy destruction is identified as the main source of extra cost. The cost rate associated with exergy destruction is higher for the biomass than the gas boiler. The reason is the higher exergy destruction flow rate in the biomass.

\subsubsection{Comparison of the two cases}

The integration of the solar field causes an increase of $41 \%$ of the investment cost rate of the system. The reason is that the investment cost of the solar field is added to the ones of the two boilers but the operating time of the system remains the main ( 8,760 hours). As seen in 4.1., the integration of the solar field decreases the operating time of the boilers. Therefore, the associated investment cost rates increase: for each hour of operation, using the boilers is more expensive than without the solar field. An increase of $12 \%$ of the product cost associated with the system is observed with the integration of the solar field. The comparison of the mean values of the relative cost difference of the global system in the two cases shows an increase of the extra costs with the solar field. The mean value of the cost associated with exergy destruction does not vary significantly while the exergoeconomic factor increase by $27 \%$. This highlights that the solar field investment cost impacts significantly the specific cost of the heat during the installation lifetime. The increase of the extra costs is more important during the nonheating, when the solar fields operates mostly, than during heating season. The low value of the cost of exergy destruction in the solar field is due to the low value of the specific fuel cost. Indeed, as the sun exergy is free, the only costs are the electricity for the pumps and, when discharging, the cost of the 
stored heat in the tank. Therefore, the high specific cost product and the high relative cost difference of the solar field are due to the investment cost rate. The high standard deviation of the cost of exergy destruction is due to high values of to the high value of specific fuel cost during the discharge of the thermal storage, whose investment cost is divided by a low operating time. An analysis of the product cost, relative cost difference and exergoeconomic factor of each boilers shows the impact of the solar on them. With the solar field, the specific product cost of the gas boiler increases by $8 \%$ during the nonheating season. An increase of its relative difference cost and its exergoeconomic factor is also observed. This shows that the integration of the solar field degrades the gas boiler from an exergoeconomic point of view. For the biomass boiler, the variations of its specific product cost and of the extra costs between the two cases are neglectful. However, the exergoeconomic factor increases both during heating and non-heating season, because of the rise of the investment cost rate.

\section{Conclusion}

In this work the effect of the integration of a solar field in an existing district heating has been investigated. It has been shown that from an exergy point of view it results in a degradation of the system by increasing the exergy destruction, particularly in the non-heating season when it is the source of $26 \%$ of the exergy destruction. The exergoeconomic analysis has demonstrated that with the solar field the cost associated to exergy destruction does not vary significantly but has also highlighted a large increase of the extra costs and has determined that the solar field is the source of it, because of an important investment cost. The integration of the solar field increases by $13 \%$ the specific exergy cost of the heat during the non-heating season. It has been demonstrated that the addition of a solar field reduces the operating cost of the two boilers and thus causes an increase of the investment cost rates. In the gas boiler, this leads to a higher specific product cost. From an exergoeconomic point of view, the performances have been degraded by the integration of the solar field for both the overall system and the gas boiler.

These results highlight that the integration of solar field in a existing $\mathrm{DH}$ can lead to a negative impact on the overall system efficiency. The addition of a seasonal storage and/or an optimisation of the control strategy could be an interesting solutions to tackle this issue. Furthermore, It would be interesting to assign an environmental cost to each heat producer, to get a more complete assessment of the solar field integration impact.

\section{Acknowledgments}

The authors wish to thank ANR (French National Research Agency) for funding this work in the frame of the SunSTONE project (ANR-17-CE05-0035-01) and the city of Chateaubriant for their collaboration.

\section{Nomenclature}

\begin{tabular}{|c|c|}
\hline$A_{p}$ & collector's aperture area, $\mathrm{m}^{2}$ \\
\hline$a_{1}$ & $\begin{array}{l}\text { first degree coefficients of } \\
\text { collector heat losses, W.K. } \mathrm{K}^{-1} \cdot \mathrm{m}^{-2}\end{array}$ \\
\hline$a_{2}$ & $\begin{array}{l}\text { second degree coefficients of } \\
\text { collector heat losses, W. } \mathrm{K}^{-2} \cdot \mathrm{m}^{-2}\end{array}$ \\
\hline$\dot{C}$ & cost rate, $€ . \mathrm{h}^{-1}$ \\
\hline$c$ & specific cost, $€ . \mathrm{kWh}^{-1}$ \\
\hline$c_{e f f}$ & $\begin{array}{l}\text { effective thermal capacity } \\
\text { collector, J.K-1. } \mathrm{m}^{-2}\end{array}$ \\
\hline$c_{p}$ & specific heat capacity, J.kg-1. $\mathrm{K}^{-1}$ \\
\hline Ex & exergy flow rate, $\mathrm{kW}$ \\
\hline$E x$ & exergy, kJ \\
\hline$e x$ & specific exergy, J. kg-1 \\
\hline$f$ & exercoeconomic factor \\
\hline G & solar irradiance, W. $\mathrm{m}^{-2}$ \\
\hline$h$ & specific enthalpy, J.kg-1 \\
\hline$I_{p}$ & incident solar irradiance, W.m-2 \\
\hline$i$ & investment rate, $\%$ \\
\hline$K$ & incidence angle modifier \\
\hline
\end{tabular}

$\begin{array}{ll}\dot{m} & \text { mass flow rate, } \mathrm{kg} . \mathrm{s}^{-1} \\ N_{\text {layers }} & \text { number of discretization layers } \\ n & \text { equipment life time, } \mathrm{yr} \\ p & \text { pressure, bar } \\ \dot{Q} & \text { heat flow rate, } \mathrm{kW} \\ r & \text { relative cost difference } \\ s & \text { specific entropy, } \mathrm{J}^{\mathrm{kg}}{ }^{-1} . \mathrm{K}^{-1} \\ T & \text { temperature, } \mathrm{K} \\ t & \text { time, } \mathrm{h} \\ \dot{W} & \text { electrical power, } \mathrm{kW} \\ \dot{Z} & \text { investment cost rate, } € \text {. } \mathrm{h}^{-1} \\ Z & \text { investment cost, } € \\ G r e k \text { symbols } \\ \eta & \text { efficiency } \\ \eta_{0} & \text { collectors zero-loss efficiency } \\ \theta & \text { solar incident angle, }{ }^{\circ}\end{array}$

Subscripts

0 reference state 


$\begin{array}{llll}\text { amb } & \text { ambient } & \text { in } & \text { inlet } \\ b & \text { direct radiation } & \text { mean } & \text { mean } \\ \text { biomass } & \text { biomass boiler } & \text { op } & \text { operation } \\ \text { bottom } & \text { bottom of the stratified storage tank } & \text { out } & \text { outlet } \\ \text { coll } & \text { solar collectors } & P & \text { product } \\ D & \text { destruction } & P 1 & \text { pump 1 } \\ d & \text { diffuse radiation } & P 2 & \text { pump 2 } \\ \text { end } & \text { end of charging stratified storage tank } & \text { sd } & \text { standard deviation } \\ \text { ex } & \text { exergy } & \text { start } & \text { start of charging stratified storage tank } \\ F & \text { fuel } & \text { sun } & \text { sun } \\ f u e l & \text { fuel of a boiler } & \text { tank } & \text { stratified storage tank } \\ f u l l o a d & \text { operating at full load } & \text { top } & \text { top of the stratified storage tank } \\ \text { gas } & \text { gas boiler } & W & \text { electrical power } \\ \text { HX } & \text { heat exchanger } & w & \text { water }\end{array}$

\section{References}

[1] Winterscheid C., Dalenbäck J.-O., Holler S., Integration of solar thermal systems in existing district heating systems. Energy 2017;137:579-85.

[2] Carpaneto E., Lazzeroni P., Repetto M., Optimal integration of solar energy in a district heating network. Renew. Energy 2015;75:714-21.

[3] Li H., Svendsen S., Energy and exergy analysis of low temperature district heating network. Energy 2012;45(1):237-46.

[4] Alkan M. A., Keçebaş A., Yamankaradeniz N., Exergoeconomic analysis of a district heating system for geothermal energy using specific exergy cost method. Energy 2013;60:426-34.

[5] Torío H., Schmidt D., Development of system concepts for improving the performance of a waste heat district heating network with exergy analysis. Energy Build.2010;42(10):1601-09.

[6] Meesenburg W., Ommen T., Elmegaard B., Dynamic exergoeconomic analysis of a heat pump system used for ancillary services in an integrated energy system. Energy 2018;152:154-65.

[7] Sayadi S., Tsatsaronis G., Morosuk T., A New Approach for Applying Dynamic Exergy Analysis and Exergoeconomics to a Building Envelope. ECOS 2016: Proceedings of the 29th International Conference on Efficiency, Cost, Optimisation, Simulation and Environmental Impact of Energy Systems, 2005 Jun 19-23; Portorož, Slovenia.

[8] Solar radiation Data. SoDa - Available at:<http://www.soda-pro.com/> [accessed 21.5.2021].

[9] Gelaro R. et al., The Modern-Era Retrospective Analysis for Research and Applications, Version 2 (MERRA-2). J. Clim. 2017;30(14):5419-54.

[10] HelioClim-3 Archives Info - Available at:<http://www.soda-pro.com/webservices/radiation/helioclim-3-archives/info> [accessed 21.5.2021].

[11] Pons M., On the Reference State for Exergy when Ambient Temperature Fluctuates. Int. J. Thermodyn. 2009;12(3):113-121, sept. 2009.

[12] Sangi R., Jahangiri P., Thamm A., Müller D., Dynamic exergy analysis - Modelicaß-based tool development: A case study of CHP district heating in Bottrop, Germany. Therm. Sci. Eng. Prog. 2017;4:231-40.

[13] Spanner D. C., Introduction to thermodynamics, 3. printing. London, UK: Academic Press; 1969.

[14] Lazzaretto A., Tsatsaronis G., SPECO: A systematic and general methodology for calculating efficiencies and costs in thermal systems. Energy 2006;31(8):1257-89.

[15] Osório T., Carvalho M. J., Testing of solar thermal collectors under transient conditions, Sol. Energy 2014;104:71-81.

[16] Dinçer İ., Rosen M., Thermal energy storage: systems and applications, 2nd ed. Hoboken, N.J: Wiley; 2011. 